\section{Terminal ileitis: Yersinia enterocolitica isolated from faeces}

There is increasing evidence that yersinia infection may play an important part in the causation of terminal ileitis. ${ }^{1}$ We report a case in which the organism was isolated from faeces for the first time in the United Kingdom.

\section{Case report}

A boy aged 13 was admitted to hospital on 2 August 1976 with two days' history of malaise and nausea. He had had constant lower abdominal pain with occasional colic for 24 hours, gradually localising to the right iliac fossa. He passed two soft stools on 1 August and one on 2 August. He was in Devon from 17 July to 1 August and had been playing with limpets, crabs, jelly fish, and sheep. There were no pet animals. He had never left England. His oral temperature was $39^{\circ} \mathrm{C}$. There was tenderness of the lower abdomen, particularly in the right iliac fossa. Laparotomy showed that the terminal $20 \mathrm{~cm}$ of ileum and its mesentery was thick, oedematous, and congested. The mesenteric lymph nodes and the rest of the bowel looked normal.

A stool specimen eight days after operation grew Yersinia enterocolitica biotype 4 (Wauters), serotype $0: 3$. The specimen was plated on desoxycholate-citrate agar. After 18 hours' incubation at $37^{\circ} \mathrm{C}$ there was a heavy growth of minute lactose non-fermenting colonies. The organism was identified by conventional methods and by API 20E (API Laboratory Products Ltd). It was not isolated from selenite broth incubated at $37^{\circ} \mathrm{C}$ for 18 hours or at $4 \mathrm{C}$ for seven days, but was recovered from phosphate buffered saline incubated at $4 \mathrm{C}$ for seven days. ${ }^{2}$ Subsequent faecal samples also grew the organism (figure). It was not isolated from the mesenteric lymph node or the swab from the serosa of the ileum, or from a rectal swab the day after operation. A rising antibody titre to the organism isolated was found and likewise to a standard strain of $Y$ enterocolitica (figure). The biopsy of the lymph node showed mild reactive follicular hyperplasia and small lymphocytes with scanty small pyroninophilic cells in the peripheral sinuses. Concentrations of serum aspartate aminotransferase, lactic acid dehydrogenase, alkaline phosphatase, and orosomucoids (figure) were raised initially, but returned to normal later. Erythrocyte sedimentation rate ranged from 4-23 mm in one hour.

Normal findings included: throat swab; chest $x$-ray pictures; electrocardiogram; antistreptolysin titre; concentrations of serum proteins, calcium, bilirubin, iron, immunoglobulins $G, A$, and $E$, cholesterol, folic acid, and red-cell folate; iron-binding capacity; result of xylose absorption test; urine culture; and virus serology. The Mantoux test was negative at a titre of $1 / 10000$. The result of a follow-through barium-meal examination was normal.

Treatment with co-trimoxazole $120 \mathrm{mg}$ twice daily was started on 16 September to relieve pain. The organism was sensitive to the drug. Blood and faeces from his parents and two sisters failed to show evidence of infection. The source of the infection remains unknown.

\section{Comment}

Although acute $Y$ enterocolitica infection of the gut has been recognised, ${ }^{4}$ it is not commonly diagnosed in the United Kingdom. ${ }^{5}$ The

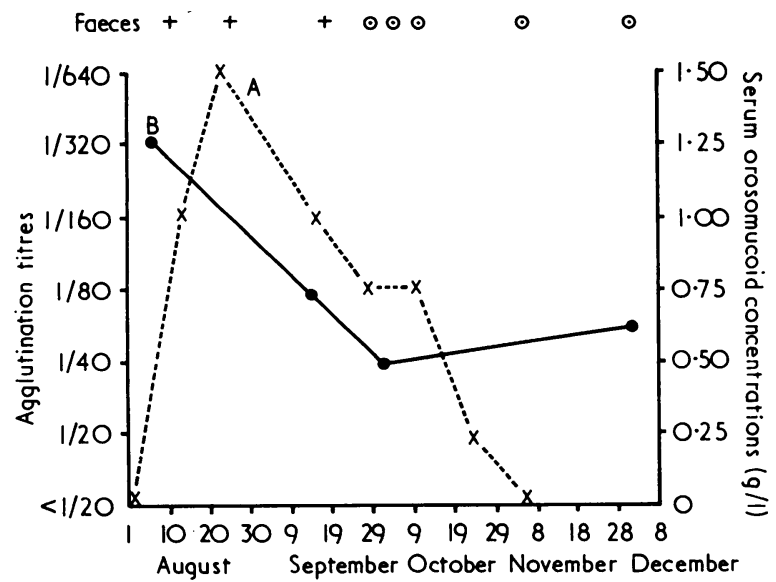

Results of laboratory investigations showing growth $(+)$ or lack of growth $(\odot)$ of Yersinia enterocolitica in patient's faeces, agglutination titres to $Y$ enterocolitica (A), and serum orosomucoid concentrations (B). organism is slow-growing and readily overlooked, but it may grow on routine culture media. If the laboratory staff are informed of the possibility of yersiniosis, the specimen may be incubated at $30^{\circ} \mathrm{C}$ for an extended time or on special media. ${ }^{2}$ Antibody titres and raised orosomucoid concentrations indicate the activity of the disease. A serological diagnosis requires the examination of paired sera samples at 10-day intervals as antibodies may not be detected in the first sample.

This case shows the importance of considering $Y$ enterocolitica infection in the differential diagnosis of acute ileitis. The outlook for patients with Crohn's disease is a serious recurring illness but those with yersinia infections may expect complete recovery.

We thank Mrs Pamela Jackson for the secretarial work.

${ }^{1}$ Nilhen, B, Acta Pathologica et Microbiologica Scandinavica, 1969 (suppl), 206, 26.

2 Toma, S, and Deidrick, V R, fournal of Clinical Microbiology, 1975, 2, 478

${ }^{3}$ Ahlqvist, J, et al, Acta Pathologica et Microbiologica Scandinavica, section A, $1971,79,109$

${ }^{4}$ Delorme, J, et al, Canadian Medical Association fournal, 1974, 110, 281.

${ }^{5}$ Chessum, B, et al, British Medical fournal, 1971, 3, 466.

(Accepted 18 March 1977)

\section{East Birmingham Hospital, Birmingham B9 5ST}

N V DORAISWAMY, MS, FRCS, registrar, department of paediatric surgery A B M CURRIE, MD, FRCS, consultant, department of paediatric surgery J GRAY, MRCPATH, DIPBACT, assistant microbiologist, public health laboratory

C LYNTON-MOLL, FIMLS, senior technician, public health laboratory

Public Health Laboratory, Groby Road Hospital, Leicester LE3 9QE N S MAIR, FRCPATH, DIPBACT, director

\section{Acute suppurative thyroiditis caused by Escherichia coli}

Suppurative thyroiditis is a rare disease which may be mistaken for other thyroid lesions. ${ }^{1}$ The usual pathogens are Gram-positive cocci. Gram-negative bacilli seldom cause thyroiditis.

\section{Case history}

A 70-year-old woman had a functioning nontoxic right thyroid nodule for three years. In July 1975 she presented with a five-day history of a sudden rapid increase in the size of the nodule, associated with redness of the overlying skin. Her temperature was $38^{\circ} \mathrm{C}$ and pulse rate $100 / \mathrm{min}$. There was a $7 \times 4 \mathrm{~cm}$ firm tender mass in the right thyroid lobe. The overlying skin was warm and erythematous. The leukocyte count was $16.1 \times$ $10^{9} / 1\left(16100 / \mathrm{mm}^{3}\right)$ and the erythrocyte sedimentation rate $112 \mathrm{~mm}$ in the first hour. Serum thyroxin, measured by competitive protein binding, ${ }^{2}$ was $80 \mathrm{nmol} / \mathrm{l}(6 \cdot 2 \mu \mathrm{g} / 100 \mathrm{ml})$, normal range $64-167 \mathrm{nmol} / \mathrm{l}(5-13 \mu \mathrm{g}$ / $100 \mathrm{ml}$ ). Urine analysis showed pyuria, and urine culture yielded a heavy growth of Escherichia coli. Blood cultures were negative. Chest radiography showed the trachea to be shifted by a soft-tissue mass at the base of the neck. A sodium pertechnetate thyroid scan showed a $2.5 \mathrm{~cm}$ functional nodule in the right lobe, corresponding in location to the palpable mass, but contributing only partly to its size. There was no uptake in the left thyroid lobe.

Within a few days the thyroid mass enlarged and became more tender. Incision yielded $30-40 \mathrm{ml}$ of a green-yellow pus which on culture grew $E$ coli with antibiotic sensitivity identical with that of the organism isolated from the urine. Treatment with gentamicin, $80 \mathrm{mg}$ eight-hourly for 10 days, resulted in complete healing of the infection. The urine culture became sterile.

\section{Comment}

The early stages of acute suppurative thyroiditis may be difficult to diagnose, and may be mistaken for subacute thyroiditis or other conditions such as acute haemorrhage into a pre-existing thyroid adenoma or cyst, rapidly growing anaplastic thyroid carcinoma, and rarely acute flare-up of Hashimoto's disease. ${ }^{1}$ 
Suppuration of the thyroid occurs as a secondary phenomenon, the primary focus being most commonly in the upper respiratory tract. $^{3}$ The commonest infecting organisms are streptococci, staphylococci, and pneumococci. ${ }^{4}$ Gram-negative bacilli rarely cause thyroiditis. In our patient the urinary tract was the probable primary focus of infection. Interestingly, the infecting organism was found in the functional nodule of the thyroid. Although the pathogenesis of this phenomenon is not clear, in acute thyroiditis the infection tends to develop in pre-existing lesions, particularly adenomas. ${ }^{4}$

\section{References}

1 Volpe, $\mathrm{R}$, in The Thyroid, ed S Werner, 3rd edn, p 847. New York, Harper and Row, 1971.

${ }^{2}$ Murphy, B E, and Pattee, C J, fournal of Clinical Endocrinology and Metabolism, 1966, 26, 99.

3 Szego, P L, and Levy, R P, Canadian Medical Association Fournal, 1970, 103, 631 .

4 Altemeier, W A, Archives of Surgery, 1950, 61, 76.

(Accepted 8 March 1977)

Department of Internal Medicine, American University Medical Centre, Beirut, Lebanon

FAYSAL SAKSOUK, MD, research fellow, division of endocrinology IBRAHIM S SALTI, MD, FRCP(C), associate professor, division of endocrinology

\section{Safety cabinet for use in laboratory studies on hazardous infectious diseases}

Patients with highly infectious diseases such as Lassa fever have large amounts of virus in their blood during the acute clinical phase. Virus may also be present in their urine, cerebrospinal fluid, and throat and other secretions. Tests on specimens of these fluids are thus potentially lethal procedures, which most clinical laboratories cannot safely undertake. Nevertheless, tests may be essential to aid diagnosis and guide treatment.

To reduce the risk of infection inactivation by heat $\left(60^{\circ} \mathrm{C}\right.$ for 60 minutes) has been considered. This, however, may not always destroy all infectivity, cannot be used on samples for bacteriological or haematological study, and changes unpredictably the concentrations of some serum constituents ${ }^{1}$. We have therefore rejected heat inactivation of plasma as not reliable enough for routine use; furthermore, the thermal stability of a new agent may not even have been examined. The safest procedure for handling dangerously infectious specimens is to contain all such material at all times within a safety cabinet. Even laboratories that would rely on heat inactivation need a cabinet for bacteriology, haematology, and the separation of plasma and serum. I describe here a slightly larger cabinet that accommodates the few additional instruments necessary for most common clinical biochemical measurements.

\section{Description}

The cabinet is an aseptic type $e^{2}$ and consists of a welded aluminium box about $200 \times 90 \times 60 \mathrm{~cm}$ with an extension at one end for the microscope (see figure). At the other end is a gas-tight door and a liquid disinfectant-filled lock (dunk tank) through which sealed containers may be passed. The windows are of 6-mm Perspex. A sparkproof fan draws about $5.7 \mathrm{~m}^{3}$ (200 cu ft) of air/min through the cabinet, giving about 440 air changes an hour. The inlet and the outlet air is filtered through absolute glass-fibre

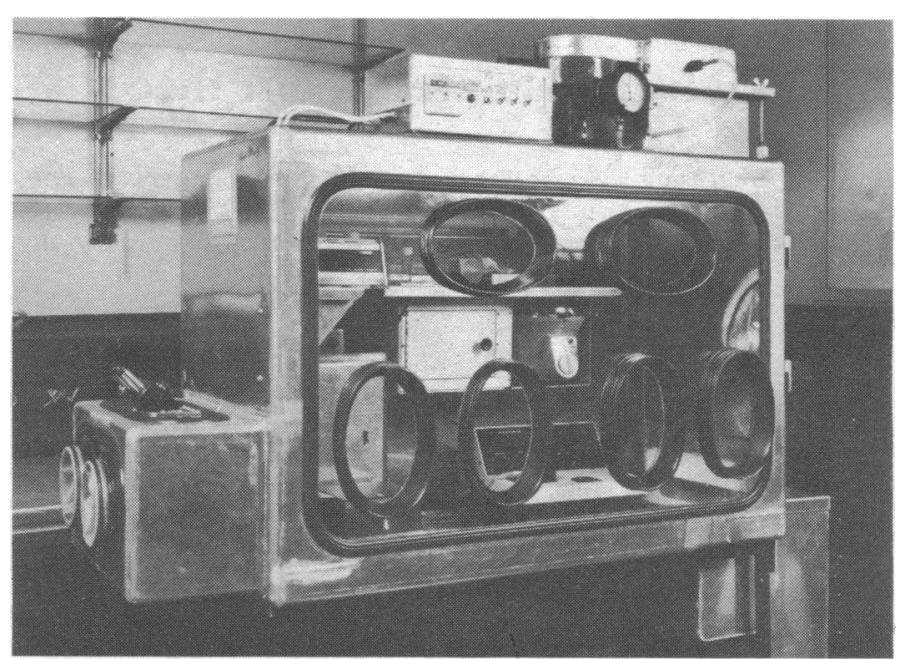

Safety cabinet with gloves removed to show interior more clearly.

paper filters that prevent the escape of infectious particles even at low airflows (when some types of filter are inefficien $t^{3}$ ), so that in the event of a power or fan failure the cabinet remains sealed. The cabinet was tested by the internal release of an aerosol containing $35.3 \times 10^{6} 1-\mu \mathrm{m}$ particles $/ \mathrm{m}^{3}$ $\left(10^{6} 1-\mu \mathrm{m}\right.$ particles/cu $\left.\mathrm{ft}\right)$ of a tracer organism and the application of a slit sampler to all possible sites of leakage. No leaks were detected with the fan either on or off.

The instruments inside were chosen for their safety, ease of use and decontamination, and reliable function after periods of inactivity. They include a microscope; a spectrophotometer with a pour-in suck-out cell and a digital display (making it easy to operate with gloves on and to read at a distance); a small incubator; and two centrifuges, one for separating 1-5-ml volumes of plasma and serum, and a microhaematocrit centrifuge (potentially a dangerous aerosol generator ${ }^{4}$ ). With these instruments routine bacteriology and haematology and a range of biochemical procedures such as plasma sugar and urea estimations and liver function tests may be carried out. Sodium and potassium may be measured by means of an unenclosed flame photometer in plasma diluted in a suitable sterilising fluid in the cabinet and passed out through the dunk tank.

\section{Conclusion}

This cabinet and the instruments within it are safe to use and easy to operate. Only existing reliable and well-tried techniques have been incorporated, partly for convenience and partly to avoid isolating too much expensive equipment that may be relatively underemployed. The cabinet has been used for haematological and biochemical investigations on blood samples from a colleague who was accidentally infected with the agent of a Marburg-like haemorrhagic fever (results to be published later).

I am most grateful to Mr D Eley, of the pathology laboratory at Salisbury General Infirmary, for investigating the effect of heat on serum; to $\mathrm{Mr}$ Charles G T Evans for much valuable advice on the design of the cabinet; and to the MRE workshop staff, especially Mr R Penney and Mr W Ducket, for constructing it.

1 Eley, D, unpublished work.

Evans, C G T, Harris-Smith, R, and Stratton, J E D, in Safety in Microbiology, ed D A Shapton and R G Board, p 21. New York, Academic Press, 1972.

3 Evans, C G T, personal communication, 1976.

- Rutter, D A, and Evans, C G T, British Medical fournal, 1972, 1, 594.

(Accepted 18 March 1977)

Microbiological Research Establishment, Porton, Salisbury SP4 0JG D A RUTTER, MB, BCHIR, principal scientific officer 